\title{
SOPHIA
}

PEER REVIEW JOURNAL

CROSSING BORDERS, SHIFTING BOUNDARIES - PHOTOGRAPHY AND ARCHITECTURE

ISSN: 2183-8976 [PRINT] 2183-9468 [ONLINE]

Volume 2, Issue 1| Publication year: 2017

DOI 10.24840/2183-8976_2017-0002_0001_03

(c) SCOPIO EDITIONS

HOMEPAGE: HTTPS:/ /WWW.SOPHIAJOURNAL.NET

\section{PHOTOGRAPHY KEEPS AN EYE ON THE PHOTOGRAPHER}

Written by Paolo Rosselli

I think we can all agree on one point, that architecture is the main territory of photography. This is the case because ever since Atget's time our way of duplicating the world has been done in the city; and probably without the city photography would not even exist. Architecture is the training ground for beginners, who take pictures of the street in which they live, shots of smoke- blackened industrial buildings or the notorious outskirts, intriguing because they provide indisputable proof of the decay of the contemporary city. Talking of decay, of squalor, no one takes photos any longer like the one of prostitutes on the corner of two narrow streets that Atget took in the twenties. Have we all turned into chaste artists who turn their gaze elsewhere?

Among the things that architecture reveals and clarifies I would definitely include the kind of connection we have with the past. Let me explain: in the city where I live Bramante is an important presence. When I come back from my travels I always meet him when I go to the bar or do the shopping. In a sense he is part of my genetic heritage, along with the contributions made by my father and mother. Well, for a while now I have been having a recurrent dream: I see Santa Maria delle Grazie wreathed in smoke and half-destroyed by a terrorist attack. But at that point, as I wake up in distress, I realize that the Milanese have brought in the best masons in Italy and that the apse (by a long chalk the part I like most) has already been largely reconstructed. A dream in step with the times, it's clear.

Now, it seems to me that this sense of hospitality is no longer part of the genetic inheritance of architecture. Mind you, this is not meant as a criticism of Bramante's successors, but contemporary architecture has become a difficult, almost intractable subject: perhaps because it no longer knows the distance between Venice and Los Angeles or between Baku and Milan; or perhaps due to the insouciance with which pops up on the aforementioned outskirts to suddenly alter their destiny. 


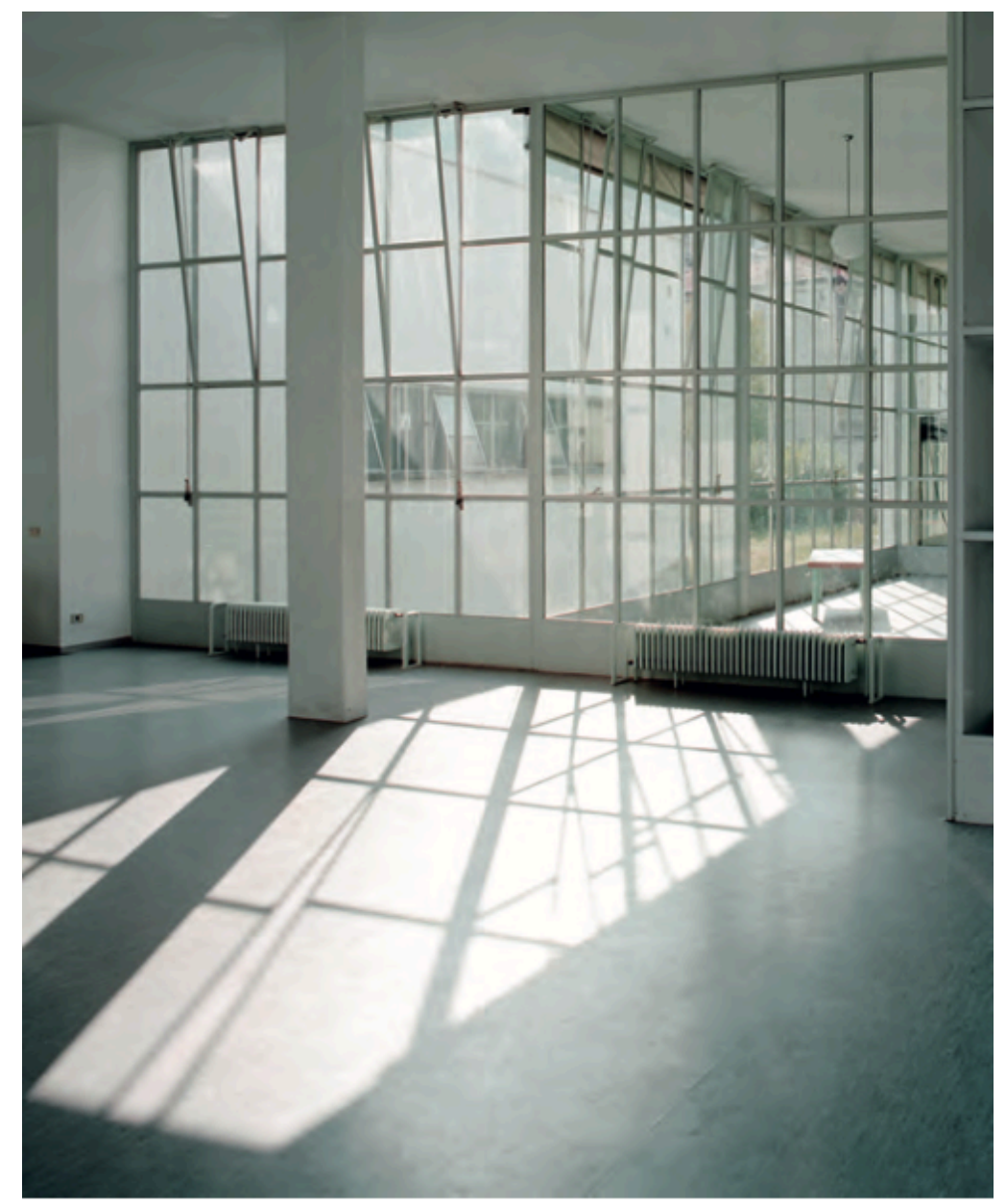

PAOLO ROSSELLI

Asilo Sant Elia, 2003

With regard to the subject of this roundtable - photography and its ability to cross boundaries - I find myself in difficulty inasmuch I am instinctively in favour of differences in language. From this perspective the century we are in now started some time ago, back in the 1980s with the frontiers crossed by large numbers of people in search of a better fate; then the frontiers were broken down by communication, by knowledge; and, at the same time, by money. In short, frontiers have no longer been taken into consideration for some time now and in a sense we should all be happy with this increase in communication.

Yet when I read that the differences between Russian and Italian poetry are inextricably bound up with the language and that this is in turn linked to a civilization I become more cautious. And, just as I would be curious to visit nearby countries that I haven't been to yet, like Romania and Hungary, I'd be equally interested to see what kind of image exists or resists in certain areas of the world. Being fairly familiar with Western European poetics, I would be interested in finding out about theirs. This might also be a type of image that does not contemplate the use of adjectives or metaphor; one that only uses nouns, in other words a factual image... house, stone, tree trunk, mountain, road, castle. 
Given that in one way or another every photograph is an artifice, what use will the photographers who live in these other worlds make of it? Good question, an author asked about the main subject of photography, which is perception, would say. And then the fact that perception is linked to a subject world and that it also involves the infamous 'l' makes things even more complicated. Interviewing the photographer Guido Guidi about his work, I obtained this response: "In general I'm attracted to elements that persist in time, but that do not have an intrinsic value... In addition, I have to say that I don't take pictures of the kitsch because I don't like it; that's all"'. (A brief digression: postmodern subjects, that is to say phoney ones, or trash, are favoured by some photographers in that they attract the public and make life easy for the critic, who can roam freely from the reviled world of consumption to the objet trouvé).

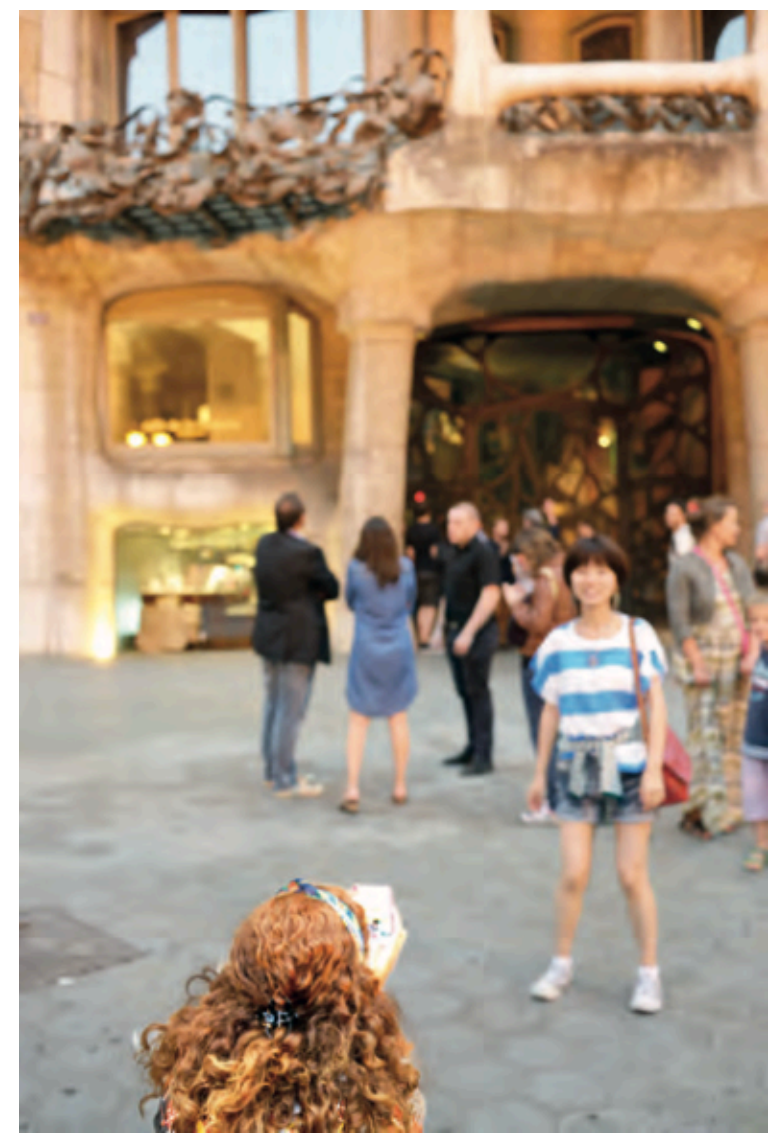

PAOLO ROSSELLI

Barcelona, 2013

Now, if I think of the criteria used to photograph the set of elements we call architecture, I must confess that I know only seventy per cent of them; and for the remaining thirty I remain a quiet and diligent child awaiting revelation from on high. To keep things simple, I'd say that I translate reality into diagrams, schemes, solids and voids, dividing the rectangle of the photograph into two squares, one of which counterbalances the other. Pared to the bone, the actions are these. I have little truck with the sense of perspective in photography and with any vision that bestows some kind of order on reality: after seeing Piero della Francesca's "Flagellation in Urbino", I came to the conclusion that the Renaissance concept of perspective

\footnotetext{
1 Interview with Guido Guidi by Paolo Rosselli, September 2015.
} 
precisely because of its perfection has been taken too seriously and that we can allow ourselves some liberties.

If someone were to ask whether I rely on concepts to guide my work, I would say for sure. I love concepts as they have the power to distance me from reality. These concepts are nothing but invisible and floating images or ones that have yet to be created which derive from my observations of the state of the world. For my convenience I turn them into expressions, into neutral terms like (to cite two that begin with the letter c) compression and climate. The first word -compression- describes the visual levels that are piled one on top of the other in the photograph. The second -climate- is for me a synonym of city: the city is not history, and still less hierarchy. It is the realm of the artificial. In a nutshell, these are my personal accelerators of images: my inspiring muses are just words.

After all the photographer is inclined to develop an idiom of his own; it is, in a manner of speaking, in his nature. And architecture, which is the art of axonometric projection, edges and duration, is happy to accept this perceptual, analytical and descriptive attention. The therapy of the image does architecture good; and there are many ways of taming it or reducing the distance between it and human beings. For its part photography has learned a lot from axonometric projections, from daring curves, from illuminated spaces: perhaps just a sense of order and continuity, of the material, but at the same time something has sunk into the negative or the digital file.

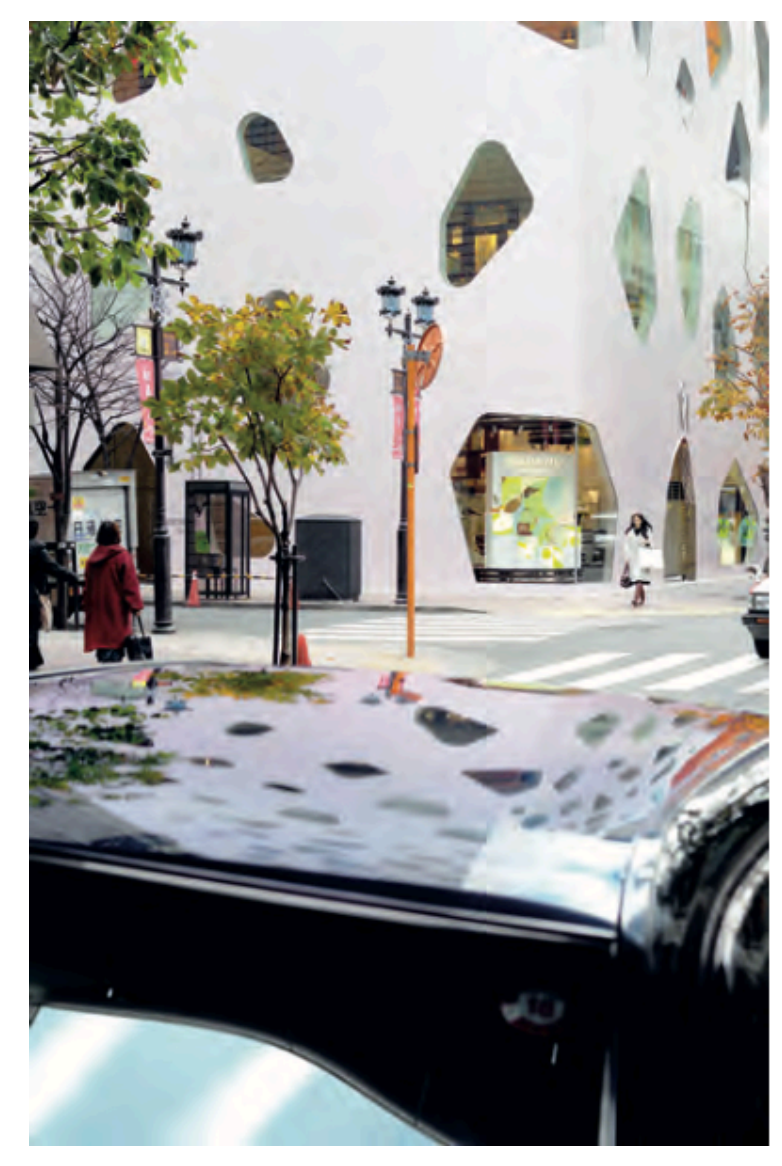


Of course, in theory every form of artistic expression should be governed by a sort of contract between its author and the real world, but we know that the best things (and images) are produced when the terms of this contract are circumvented and reshuffled and rationality starts to give way. The first city I ever photographed was a small capital that was treated condescendingly in the guidebooks, Chandigarh. I was a twenty-eight-year-old in search of emblems of history and thought that my studies would allow me to create a precise and mindful image. And yet the pictures showed the sky, the vegetation, Le Corbusier's tapering concrete, parked cars, a dozing Sikh with his legs crossed, in short the climate of a city. I ought to have known that I was the one controlled by photography and not the other way round. And that even an extraordinary architecture is unable to impose on photography its value, I mean in a historical, aesthetic sense; in other words photography is (also) the art of subversion, reconstruction, of course with the best intentions. 

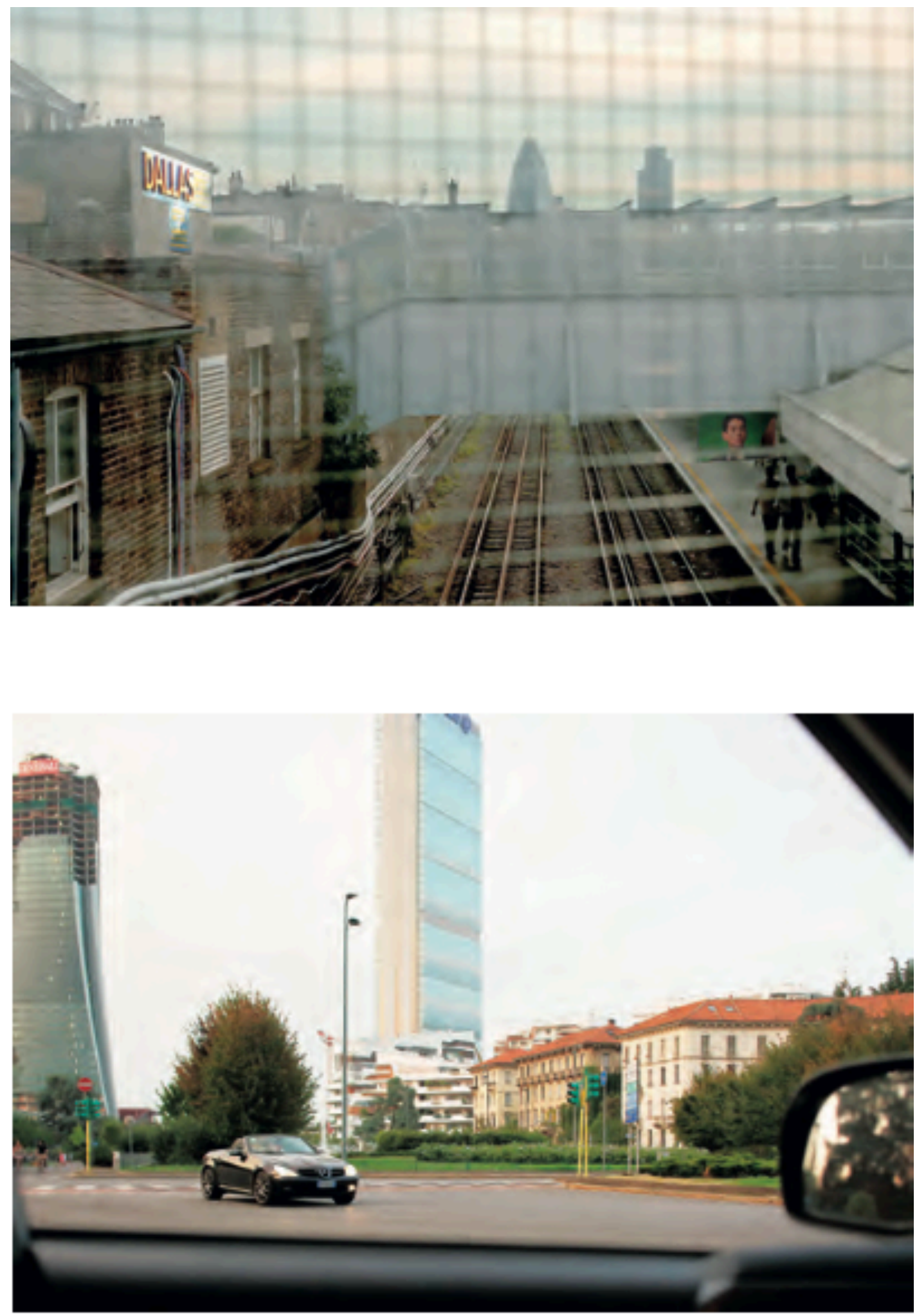

PAOLO ROSSELL

London, 2005

PAOLO ROSSELLI

Milano, 2016 


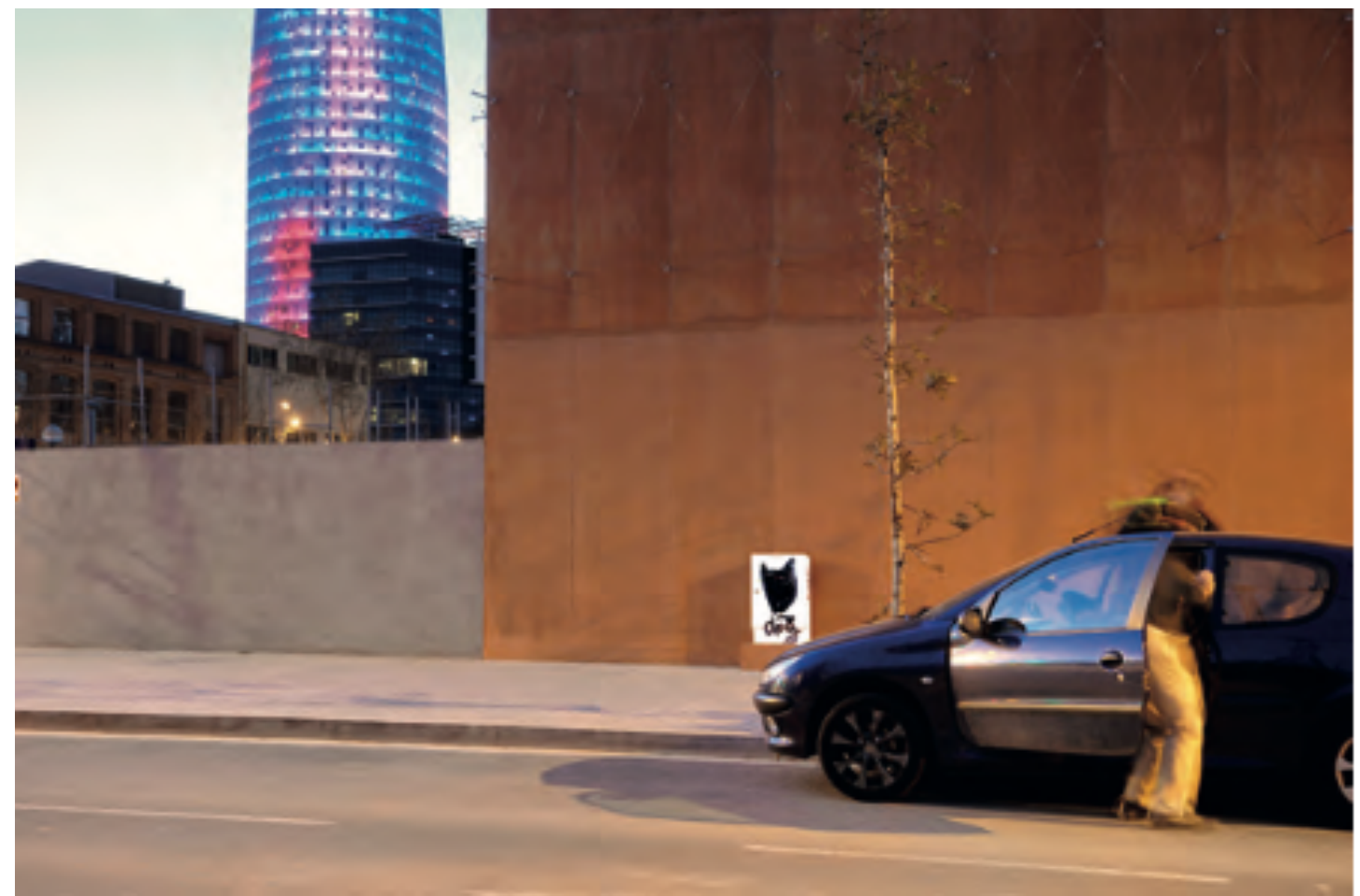

PAOLO ROSSELLI

Barcelona, 2007 


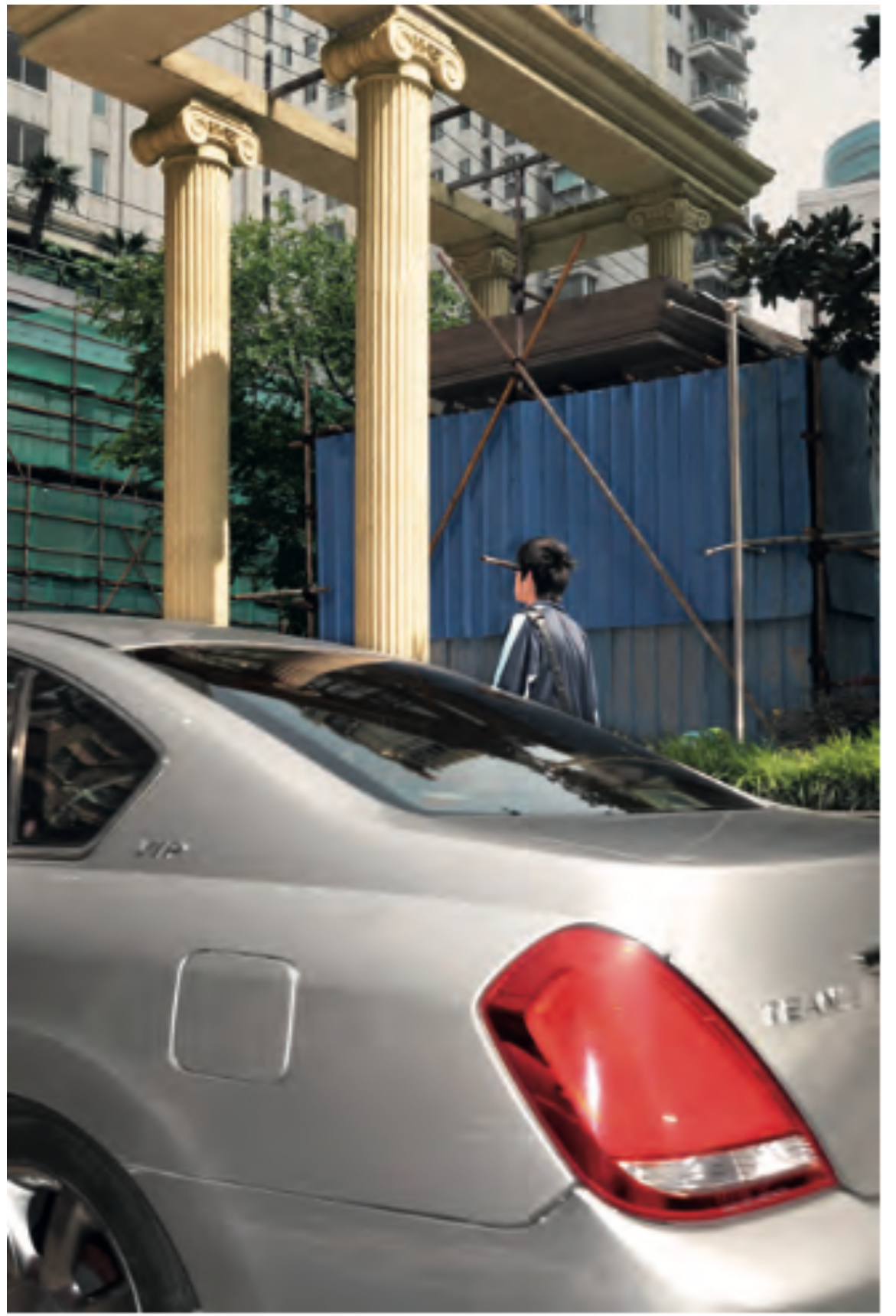

PAOLO ROSSELLI

Shangai, 2009 


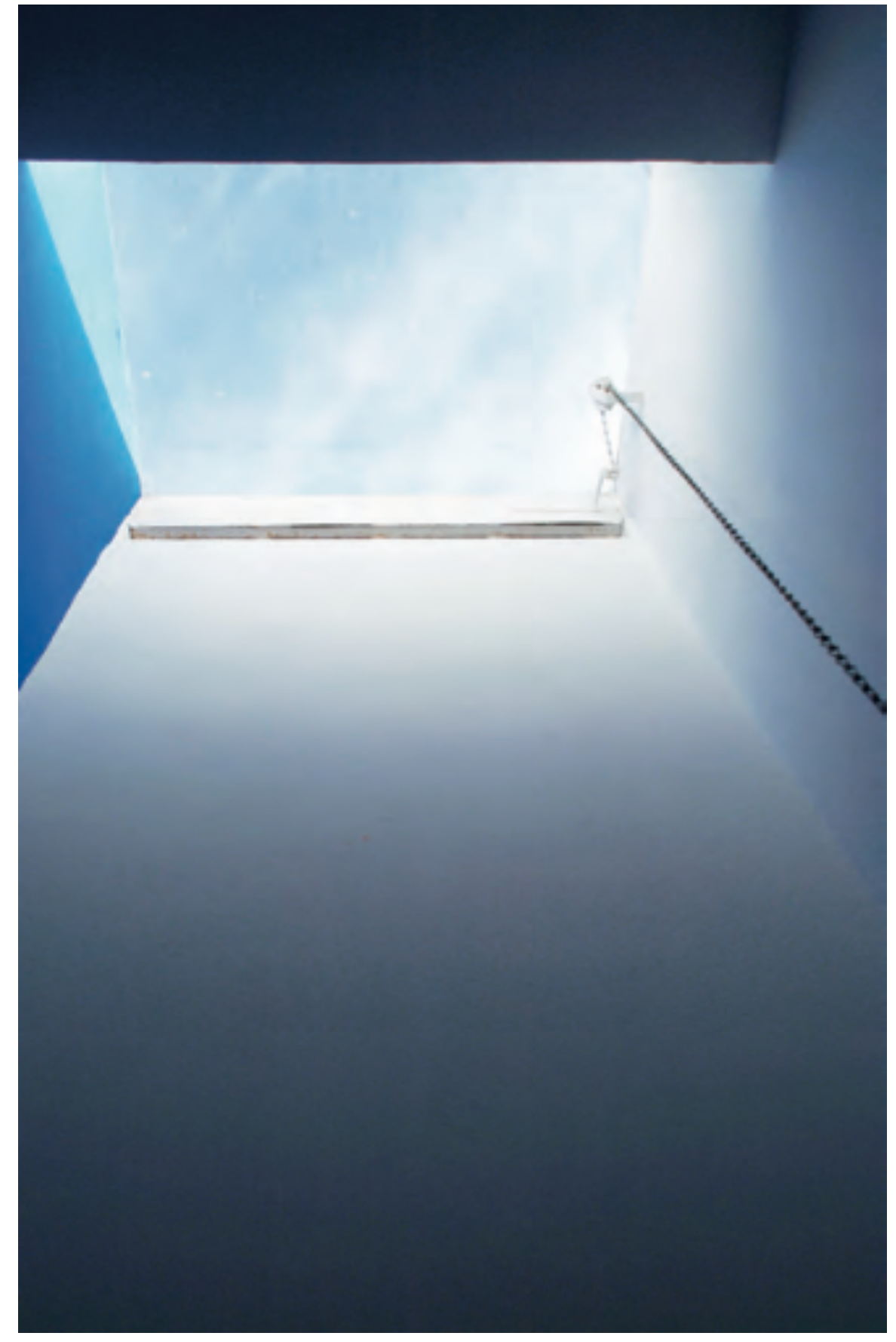

PAOLO ROSSELLI

Villa Savoye, 2003

scopio 9 


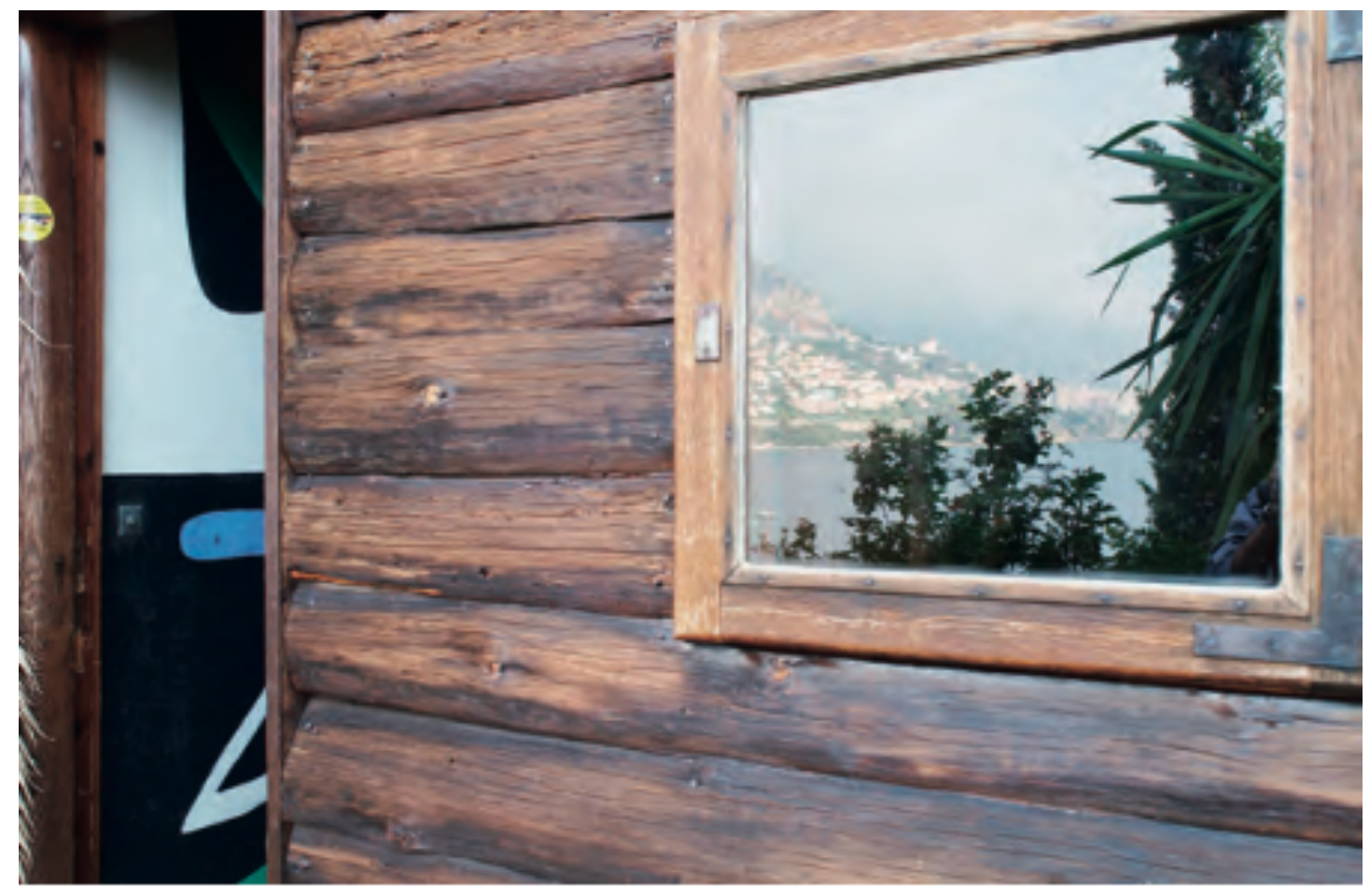

PAOLO ROSSELLI

Le Cabanon, 2003 